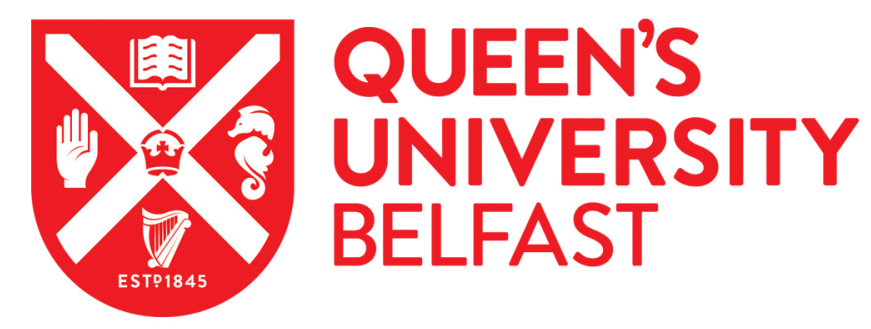

\title{
Reducing variability in apparent operative inclination during total hip arthroplasty: findings of a randomised controlled trial
}

O'Neill, C. K. J., Hill, J. C., Patterson, C. C., Molloy, D. O., Gill, H. S., \& Beverland, D. E. (2018). Reducing variability in apparent operative inclination during total hip arthroplasty: findings of a randomised controlled trial. Hip International, 28(3), 234-239. https://doi.org/10.1177/1120700018777485

Published in:

Hip International

Document Version:

Peer reviewed version

Queen's University Belfast - Research Portal:

Link to publication record in Queen's University Belfast Research Portal

\section{General rights}

Copyright for the publications made accessible via the Queen's University Belfast Research Portal is retained by the author(s) and / or other copyright owners and it is a condition of accessing these publications that users recognise and abide by the legal requirements associated with these rights.

Take down policy

The Research Portal is Queen's institutional repository that provides access to Queen's research output. Every effort has been made to ensure that content in the Research Portal does not infringe any person's rights, or applicable UK laws. If you discover content in the Research Portal that you believe breaches copyright or violates any law, please contact openaccess@qub.ac.uk. 


\title{
Reducing variability in apparent operative inclination during total hip arthroplasty: findings of a randomised controlled trial
}

\author{
Christopher K J O'Neill ${ }^{1}$, Janet C Hill ${ }^{1}$, Christopher C Patterson ${ }^{2}$, Dennis O Molloy ${ }^{1}$, Harinderjit S Gill ${ }^{3}$, David E Beverland ${ }^{1}$ \\ 1Primary Joint Unit, Musgrave Park Hospital, Belfast - UK \\ ${ }^{2}$ Centre for Public Health, Queen's University Belfast, Belfast - UK \\ ${ }^{3}$ Department of Mechanical Engineering, University of Bath, Bath - UK
}

\begin{abstract}
Aims: To determine which of 3 methods of cup insertion most accurately achieved a target apparent operative inclination (AOI) of $35^{\circ} \pm 2.5^{\circ}$ : (1) Freehand; (2) Modified Mechanical Alignment Guide (MAG); or (3) Digital Inclinometer assisted.

Methods: Using a cementless cup via a posterior approach in lateral decubitus 270 participants were recruited, with 90 randomised to each method. The primary outcome was the unsigned deviation from target AOI. The digital inclinometer was used to measure AOI in all cases, though the surgeon remained blinded to the reading intraoperatively for both the Freehand and MAG methods.

Results: Mean deviation from target AOI for the Freehand, Modified $35^{\circ}$ MAG and Digital Inclinometer techniques was $2.9^{\circ}, 1.8^{\circ}$ and $1.3^{\circ}$ respectively.

When comparing mean deviation from target AOI, statistically significant differences between the Freehand / Inclinometer groups $(p<0.001)$, the Freehand / Modified $35^{\circ}$ MAG groups $(p<0.001)$ and the Digital Inclinometer / Modified $35^{\circ}$ MAG groups $(p<0.023)$ were evident.

The Digital Inclinometer technique enabled the surgeon to achieve a target $\mathrm{AOI}$ of $35^{\circ} \pm 2.5^{\circ}$ in $88 \%$ of cases, compared to $71 \%$ of Modified $35^{\circ}$ MAG cases and only $51 \%$ of Freehand cases.

Discussion: The Digital Inclinometer and the Modified $35^{\circ}$ MAG techniques were both more accurate than the Freehand technique, with the Digital Inclinometer technique proving most accurate overall.

Radiographic inclination (RI) is also influenced by operative anteversion; however, the greatest source of error with respect to RI occurs when the pelvic sagittal plane is not horizontal at the time of acetabular component insertion.
\end{abstract}

Clinical Trial Protocol number: NCT01831401

Keywords: Acetabular component orientation, apparent operative inclination, digital inclinometer, pelvic sagittal plane, total hip arthroplasty

\section{Introduction}

The consequences of acetabular component malposition include instability, accelerated wear, impingement, bearing-related noise generation, limb length discrepancy,

Date received: 09 October 2017 accepted: 17 April 2018.

Corresponding author:

Janet C Hill

Primary Joint Unit

Musgrave Park Hospital

Stockman's Lane

Belfast BT9 7JB

UK

janet.hill@belfasttrust.hscni.net loosening and poor functional outcomes. Despite advances in surgical technique, consistent accuracy of cup placement remains challenging (1).

Postoperative radiological inclination (RI) is determined by:

- Operative version

- Apparent operative inclination (AOI)

- Orientation of the pelvic sagittal plane at the time of cup insertion.

In order to reproducibly obtain a target value for RI the surgeon must be aware of the impact of operative version and be able control the other 2 variables.

Operative version is defined as the angle subtended by the patient's longitudinal axis and the acetabular axis, when projected onto the sagittal plane (2). During surgery the longitudinal 

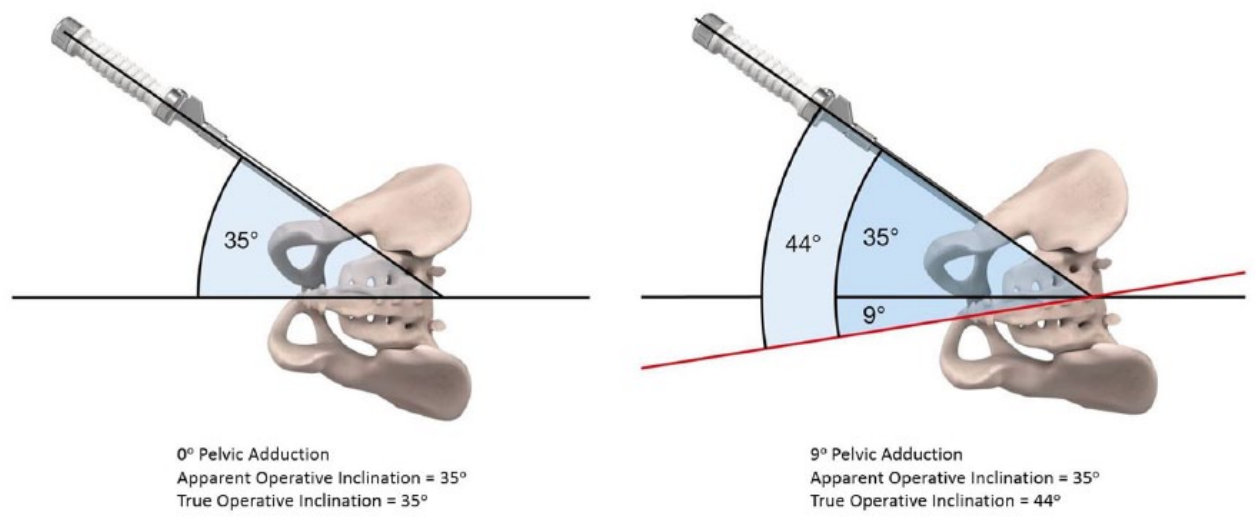

Fig. 1 - True Operative Inclination versus Apparent Operative Inclination. If the sagittal plane of the pelvis is not parallel with the floor, then Apparent OI does not equal true OI. In this example, the upper hemi-pelvis has adducted resulting in true OI being greater than Apparent OI.

axis is determined by the anterior pelvic plane which is very variable due to variation in pelvic tilt (3). The effect of this variation can be neutralised by using the transverse acetabular ligament to control cup version as it is independent of pelvic tilt $(4,5)$.

Operative inclination is defined as the angle between the acetabular axis and the sagittal plane which is why the sagittal plane is critical to inclination (2). Intraoperatively in lateral decubitus operative inclination becomes the angle between the cup handle (acetabular axis) and the theatre floor with the latter acting as a surrogate for the pelvic sagittal plane. We refer to this angle as "apparent" operative inclination (AOI) because we assume often incorrectly that the pelvic sagittal plane is parallel to the floor (Figure 1). Mathematically, for a fixed value of operative inclination as operative anteversion increases so too does $\mathrm{RI}(2,6)$. Therefore, unless the cup is retroverted, RI will always be greater than operative inclination. Consequently, the traditional jigs which are designed to give $45^{\circ}$ $\mathrm{AOI}$ if used correctly will result in radiographic inclinations greater than $45^{\circ}$. Therefore, when operating in lateral decubitus we believe the surgeon should aim for $35^{\circ}$ of $\mathrm{AOI}$ to achieve a RI of $<45^{\circ}(6)$.

This study was designed simply to determine which of 3 methods best allowed the surgeon to achieve a target angle of $35^{\circ}$ between the cup handle and the theatre floor (AOI) when inserting a cementless cup in the lateral decubitus position.

This study formed part of a factorially designed randomised controlled trial (Clinical Trial Protocol number: NCT01831401) which also investigated the effect of patient pelvic positioning on RI during THA. The latter is described in the second paper (7).

To our knowledge, there are no previously published clinical trials investigating the effect of method of acetabular component insertion on $\mathrm{AOI}$ during THA.

\section{Methods}

Study size calculations were based on data from Hill et al.,(7) with the key value being the standard deviation of $2.9^{\circ}$ for the absolute deviation from target AOI. 88 patients in each group provided $95 \%$ power to detect a difference in mean absolute deviation from target of $6.0^{\circ}$ versus $4.5^{\circ}$ versus $4.5^{\circ}$ between the 3 methods of acetabular component insertion in a 1-way analysis of variance conducted at the $5 \%$ significance level. To allow for a small number of dropouts and permit randomisation in balanced blocks of 9 patients, the study size was increased to 90 patients in each group (270 in total). The randomisation schedule was generated using Stata Release 11 (StataCorp, College Station, TX, USA). Medicines and Healthcare Products Regulatory Agency and Regional Ethics Committee approval was obtained (Ref:12/ $\mathrm{NI}$ (0191). The CONSORT recommendations were followed (see supplementary material). All patients provided informed consent. Surgery was performed by 1 of 2 high-volume arthroplasty surgeons.

In all cases, the cementless Pinnacle Acetabular System (DePuy Synthes, Leeds, UK) was used. Pinnacle 100 series shells were implanted in $269 / 270$ cases. In $1 / 270$ cases, a spiked Pinnacle 300 series shell was implanted to augment primary component stability. All cases were performed in lateral decubitus via a posterior approach. Patients were positioned using a standardised technique and by the same individual $\left(\mathrm{CO}^{\prime} \mathrm{N}\right)$, using the Universal Lateral Positioner System (Innovative Medical Products, CT, USA) to provide 3-point pelvic support.

Patients were randomised to 1 of 3 methods for acetabular component insertion: Freehand, Modified $35^{\circ}$ Modified Mechanical Alignment Guide (MAG) or Digital Inclinometer. In all cases target $\mathrm{AOI}$ was $35^{\circ}$. With the Freehand technique, the surgeon estimated $\mathrm{AOI}$, using the theatre floor as a horizontal reference. As standard commercially available MAGs provide reference for $45^{\circ}$, a modified $35^{\circ}$ MAG (DePuy Synthes, Leeds, UK) was manufactured to allow more direct comparison of techniques (Figure 2a). As TAL was used to control version, the Modified MAG did not include a version guide. With the Digital Inclinometer assisted technique, a digital inclinometer (Digi-Pas DWL-80E, DigiPas USA, CT, USA) placed within a sterile arthroscopy 

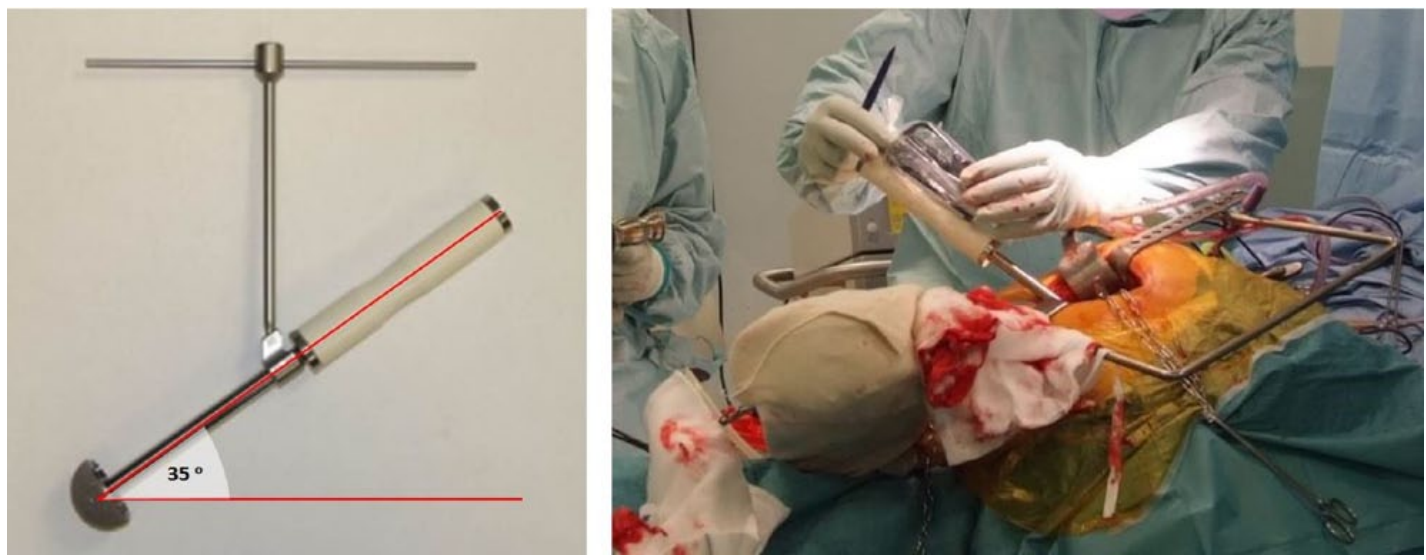

Fig. 2a - Modified $35^{\circ}$ MAG.

Fig. 2b - Digital Inclinometer assisted technique.

camera drape (Microtek Medical BV, Zutphen, Netherlands) was used to control AOI. At the time of component positioning and impaction, the digital inclinometer was placed on the acetabular component insertion handle to provide a value for $\mathrm{AOI}$ correct to 1 decimal place (Figure $2 \mathrm{~b}$ ). The digital inclinometer was calibrated preoperatively and re-checked immediately postoperatively to ensure accuracy.

Due to an unanticipated delay in manufacture of the $35^{\circ}$ Modified MAG, a pragmatic decision to commence the study with initial randomisation to only either the Freehand or Digital Inclinometer methods was made. Consequently 78 patients were recruited prior to introduction of the $35^{\circ}$ Modified MAG. On introduction of the Modified MAG, an updated randomisation schedule was generated to ensure overall balanced randomisation to each of the 3 groups by time of study completion.

In all cases, the surgeon positioned the component and controlled AOI. Impaction was performed by an assistant. For the Freehand and Modified $35^{\circ}$ MAG techniques, an assistant measured AOI using the digital inclinometer. The surgeon remained blinded to this value intraoperatively. In all cases 3 measurements were taken for $\mathrm{AOI}$; before impaction ( $\mathrm{AOI}_{\mathrm{Before}}$ ), after first impaction $\left(\mathrm{AOI}_{\text {First }}\right)$ and after final impaction $\left(\mathrm{AOI}_{\text {Final }}\right)$. The primary outcome measure was the absolute (or unsigned) deviation from target $\mathrm{AOI}$ of $35^{\circ}$ following final impaction $\left(\mathrm{AOI}_{\text {Dev35 }}\right)$; i.e. an $\mathrm{AOI}_{\text {Final }}$ of $33.0^{\circ}$ and $37.0^{\circ}$ would both result in an $\mathrm{AOI}_{\text {Dev35 }}$ of $2.0^{\circ}$.

\section{Statistical analysis}

1-way analysis of variance (ANOVA) was followed by posthoc multiple comparison methods to compare means of quantitative variables between groups taking account of heterogeneity of variance, where present. Chi-squared tests were used to compare categorical variables between groups. Tests were conducted at the $5 \%$ significance level. Statistical analysis was performed using SPSS 20 (IBM Corp., Armonk, USA).

\section{Results}

There was no significant difference in sex $(p=0.725)$ or body mass index (BMI) $(p=0.298)$ between groups. Although a statistically significant difference in patient age existed between groups $(p=0.034)$, this was not considered to be clinically significant.

Overall the mean value of $\mathrm{AOI}_{\text {Final }}$ was $1.2^{\circ}$ less than

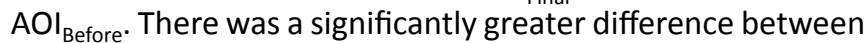
$\mathrm{AOI}_{\text {Final }}$ and $\mathrm{AOI}_{\text {Before }}$ in the digital inclinometer group when compared to the other two groups $(p<0.05)$. There was no significant difference between surgeons.

Figure 3 shows the $\mathrm{AOI}_{\text {Final }}$ distribution for each technique. Table 1 gives the overall means $\mathrm{AOI}_{\text {Final }}$ and their unsigned deviations from $35^{\circ}\left(\mathrm{AOI}_{\mathrm{Dev} 35}\right)$. The Freehand technique had the largest $A O I_{\text {Final }}$ range $\left(25.2-43.2^{\circ}\right)$. The Digital Inclinometer technique had the highest number of cases obtaining an $\mathrm{AOI}_{\text {Final }}$ of $35^{\circ}$ (rounded to the nearest degree) and an overall mean $\mathrm{AOI}_{\text {Final }}$ of $34.0^{\circ}$ which was closer to the target $\mathrm{AOI}$ of $35^{\circ}$ when compared to both the Freehand $\left(32.9^{\circ}\right)$ and Modified MAG $\left(33.7^{\circ}\right)$ techniques. Overall mean $\mathrm{AOI}_{\text {Dev35 }}$ was $2.0^{\circ}$. The Digital Inclinometer had a significantly lower mean $\mathrm{AOI}_{\mathrm{Dev} 35}\left(1.3^{\circ}\right)$ when compared to both the Modified MAG $\left(1.8^{\circ}\right)$ and Freehand $\left(2.9^{\circ}\right)$ techniques $(p<0.05)$.

For both $\mathrm{AOI}_{\text {Final }}$ and $\mathrm{AOI}_{\mathrm{Dev} 35}$ there was evidence of heterogeneity of variance between groups $(p<0.001)$, with the digital inclinometer group having the smallest standard deviation of the 3 groups for both measures.

Figure 4 shows the distribution of $\mathrm{AOI}_{\text {Dev35 }}$ values for each of the 3 methods. $58 \%$ of Digital Inclinometer cases had an $\mathrm{AOI}_{\text {Final }}$ within $1^{\circ}$ of target AOI, compared to $39 \%$ of Modified MAG cases $(p=0.01)$ and $17 \%$ of Freehand cases $(p<0.001)$. Only $1 \%$ of Digital Inclinometer cases had an $\mathrm{AOI}_{\text {Final }}$ greater than $5^{\circ}$ from target $\mathrm{AOI}$ compared to $2 \%$ and $11 \%$ of Modified MAG and Freehand cases respectively.

Our current practice aims for an AOI within a $5^{\circ}$ target range $\left(35 \pm 2.5^{\circ}\right)$. The Digital Inclinometer had $88 \%$ of cases within this target range compared to $71 \%$ and $51 \%$ of cases within the Modified MAG and Freehand groups ( $p=0.006$ and $p<0.001$ respectively).

When comparing mean $\mathrm{AOI}_{\mathrm{Dev} 35}$ there was a statistically significant difference between both the Freehand and Modified MAG groups and the Freehand and Digital Inclinometer groups $(p<0.001)$. A significant difference between the Digi- 


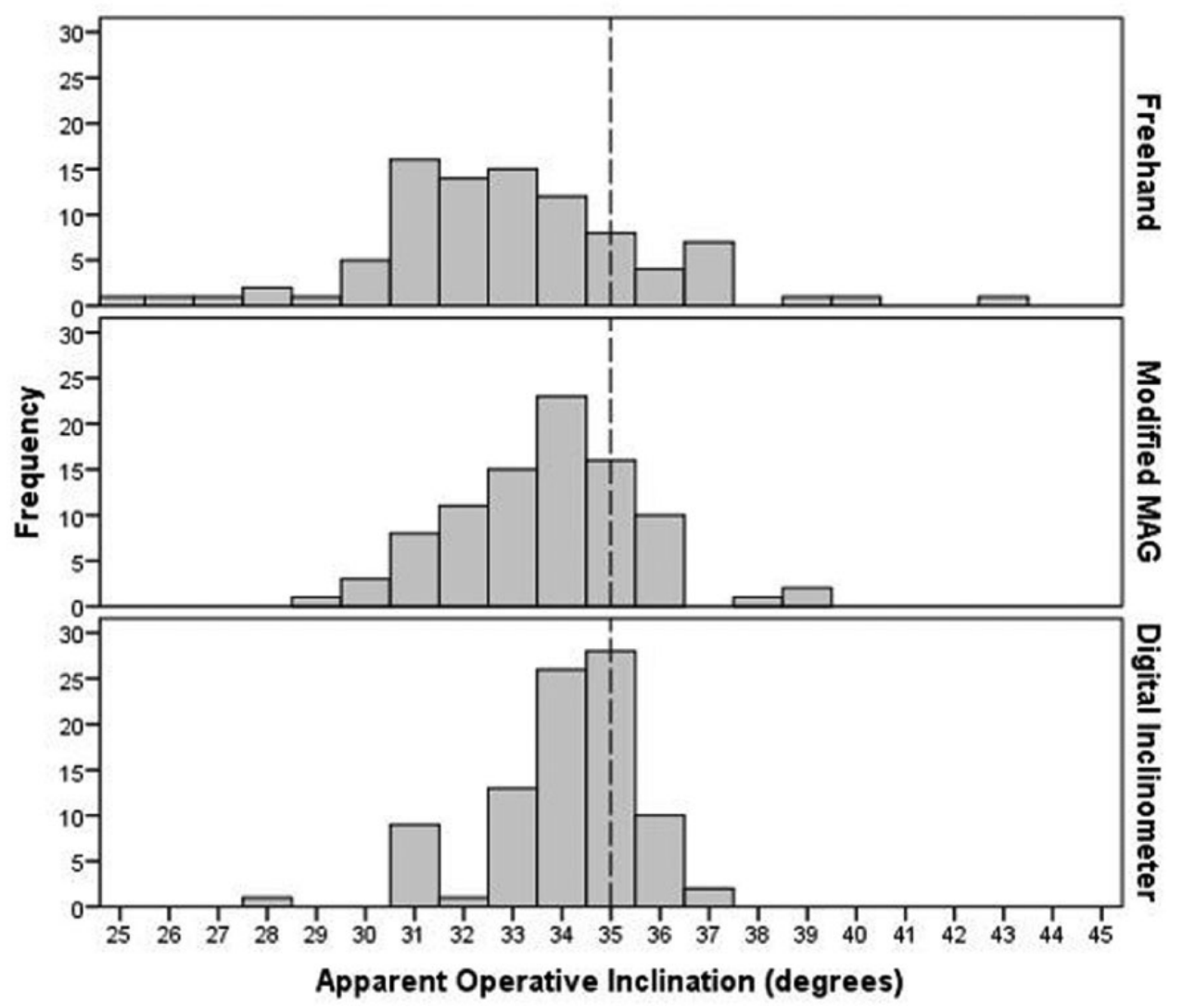

Fig. 3 - Final Apparent Operative Inclination $\left(\mathrm{AOI}_{\text {Final }}\right)$ for each group.

TABLE I - $\quad \mathrm{AOI}_{\text {Final }}$ (Apparent Operative Inclination after final impaction) and $\mathrm{AOI}_{\text {Dev35 }}$ (Final absolute deviation from target $\mathrm{AOI}$ of $35^{\circ}$ ) values for each group.

\begin{tabular}{|c|c|c|c|c|c|}
\hline & $n$ & \multicolumn{2}{|l|}{$\mathrm{AOI}_{\text {Final }}$} & \multicolumn{2}{|l|}{$\mathrm{AOI}_{\text {Dev35 }}$} \\
\hline Freehand & 90 & $32.9^{\circ}\left(2.9^{\circ}\right)$ & $25.2^{\circ}-43.2^{\circ}$ & $2.9^{\circ}\left(2.0^{\circ}\right)$ & $0.0^{\circ}$ to $9.8^{\circ}$ \\
\hline Modified MAG & 90 & $33.7^{\circ}\left(1.9^{\circ}\right)$ & $29.3^{\circ}-39.3^{\circ}$ & $1.8^{\circ}\left(1.4^{\circ}\right)$ & $0.0^{\circ}$ to $5.7^{\circ}$ \\
\hline Digital Inclinometer & 90 & $34.0^{\circ}\left(1.6^{\circ}\right)$ & $27.5^{\circ}-37.3^{\circ}$ & $1.3^{\circ}\left(1.3^{\circ}\right)$ & $0.0^{\circ}$ to $7.5^{\circ}$ \\
\hline
\end{tabular}

tal Inclinometer and Modified MAG groups was also demonstrated $(p=0.023)$. Overall the Digital Inclinometer technique was more accurate than both the Freehand and Modified MAG techniques.

Both surgeons obtained the smallest mean $\mathrm{AOI}_{\text {Dev35 }}$ when using the Digital Inclinometer, with Surgeons A and B obtaining values of $1.8^{\circ}$ and $0.8^{\circ}$ respectively. Conversely, both Surgeons obtained the largest mean $\mathrm{AOI}_{\text {Dev35 }}$ when using the Freehand technique, with Surgeons $A$ and $B$ obtaining values of $2.7^{\circ}$ and $3.1^{\circ}$ respectively.

There was a significant difference in mean $\mathrm{AOI}_{\text {Dev35 }}$ between the Freehand and Digital Inclinometer technique for both surgeons (Surgeon A, $p=0.01$, Surgeon $B, p<0.001$ ). Although the mean $\mathrm{AOI}_{\text {Dev35 }}$ was smaller for the Modified
MAG than the Freehand technique, only Surgeon B's results reached significance (Surgeon $A, p=0.55$, Surgeon $\mathrm{B}, p<0.001$ ). Although for Surgeon $\mathrm{B}$, the mean $\mathrm{AOI}_{\text {Dev35 }}$ was lower when using the Digital Inclinometer when compared to the Modified MAG $\left(0.8^{\circ}\right.$ vs. $\left.1.1^{\circ}\right)$, this difference did not obtain statistical significance $(p=0.42)$. Independent samples $t$ tests showed that there was no statistical difference between mean $\mathrm{AOI}_{\text {Dev35 }}$ for both Surgeons when using the Freehand technique $(p=0.37)$ although Surgeon $A$ had a lower mean value. There was however a significant difference in mean $\mathrm{AOI}_{\text {Dev35 }}$ between Surgeons when using the Modified MAG $(p<0.001)$ and Digital Inclinometer $(p$ $<0.001$ ), with Surgeon B having a lower mean AOI $_{\text {Dev35 }}$ for both techniques. 


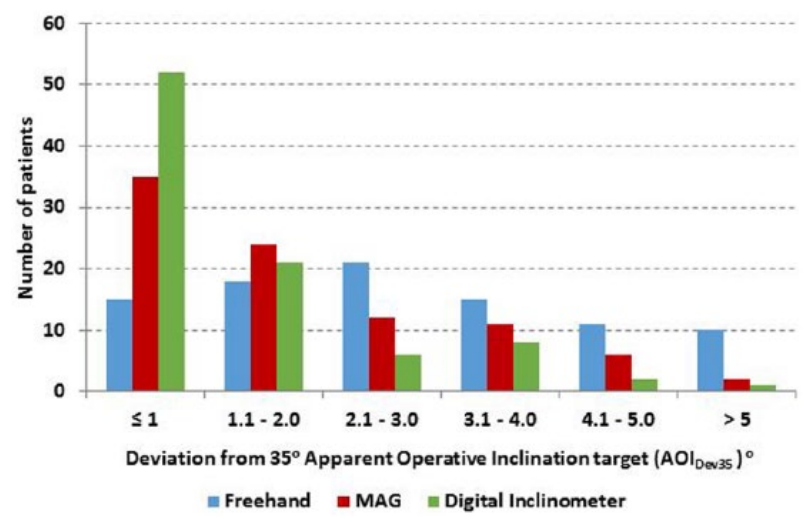

Fig. 4 - Absolute (unsigned) deviation from target $\mathrm{AOI}$ of $35^{\circ}$ following final impaction $\left(\mathrm{AOI}_{\mathrm{Dev} 35}\right)$ for each group.

\section{Discussion}

Although the digital inclinometer accurately controls $\mathrm{AOI}$ when initially positioning the acetabular component it is difficult to maintain this during impaction. The reason for this is unclear. It may be because the impact of the hammer is not parallel to the axis of the cup handle or it could be due to pelvic movement with impaction. Previous work within our unit demonstrated that $\mathrm{AOI}$ decreases by a mean of almost $2^{\circ}$ during impaction to final position,(5)however, in this study the mean difference was slightly less. In order to allow for this trend of change in AOI during impaction, when using the Digital Inclinometer technique, we recommend setting $\mathrm{AOI}$ to $37.0^{\circ}$ at time of initial component positioning.

In this study, both surgeons employed this technique when using the Digital Inclinometer rather than trying to maintain a constant AOI throughout impaction. We believe this explains the greater mean change in $\mathrm{AOI}$ from time of initial positioning to $\mathrm{AOI}$ following final impaction for the Digital Inclinometer group when compared to both the Freehand and Modified MAG groups (-2.0 $0^{\circ}$ vs. $-0.7^{\circ}$ and $-0.8^{\circ}$ respectively). It is important to note that although the Digital Inclinometer provided a greater absolute change in AOI during impaction, the actual final mean deviation from target $\mathrm{AOI}$ was lower when compared to both the Freehand and Modified MAG techniques.

It was interesting that for all 3 methods the mean $\mathrm{AOI}$ was below the $35^{\circ}$ target with an overall mean of $33.5^{\circ}$ (Table 1 ). This is perhaps down to a subconscious surgical bias towards avoiding unwanted higher inclination values.

For the Digital Inclinometer the 1 case outside the $5^{\circ}$ target range had an $\mathrm{AOI}$ of $27.5^{\circ}$. In this case the surgeon accepted this value rather than compromise cup fixation in poor quality bone.

In the other arm of this study which is reported in the second paper the range of $\mathrm{RI}$ in the same 270 patients was $24.2^{\circ}-62.6^{\circ}(6)$. For the case with the highest value of RI $\left(62.6^{\circ}\right)$ the AOI obtained intraoperatively was $35.0^{\circ}$. This difference of $27.6^{\circ}$ between $\mathrm{AOI}$ and $\mathrm{RI}$ is too large to be explained only by the effect of operative anteversion. We believe that such high values of RI are because the pelvic sagittal plane was not horizontal at the time of cup impaction with the upper hemi-pelvis being adducted and internally rotated.

This study clearly demonstrates an advantage of both the digital inclinometer and MAG over a freehand technique when aiming for a target $\mathrm{AOI}$. The problem is that published results demonstrate that even in experienced hands subsequent $\mathrm{RI}$ range is typically $\pm 20^{\circ}$ from the desired target of approximately $40^{\circ}(5)(6)(8)$. This is because the greatest source of error is the orientation of the pelvic sagittal plane and not the intraoperative variation of $\mathrm{AOI}$ or the influence of operative anteversion. Therefore, from the surgeon's perspective, with respect to cup inclination, there is often a mismatch between what is observed during surgery and the postoperative $x$-ray. For example in this study in 1 particular case the surgeon achieved a target $\mathrm{AOI}$ of $35^{\circ}$ but this became $62^{\circ}$ on the $\mathrm{x}$-ray. If as a surgical community we wish to address this problem, we need to improve our surgical supports to ensure that at the point of cup insertion the sagittal plane is horizontal when operating in lateral decubitus. Only then will the surgeon be rewarded for achieving a target AOI by using an inclinometer or MAG as opposed to the commonly used freehand method. In addition implant companies need to recognise the influence of operative anteversion and design MAGs that provide a target of $35^{\circ}$ as opposed to $45^{\circ}$ of $A O I$.

Although the digital inclinometer is very attractive and is now standard in our practice, concerns about sterility and the need for a sterile arthroscopy camera drape may limit its more widespread use. It is also possible that the results may not be directly transferable to lower volume surgeons, who may be more likely to obtain higher deviations from target AOI.

\section{Disclosures}

Financial support: This research received funding from the Belfast Arthroplasty Research Trust (BART) and DePuy Synthes.

Conflict of interest: None of the authors has financial interest related to this study to disclose.

\section{Online-only supplementary material}

CONSORT Flow Diagram.

\section{References}

1. Bhaskar D, Rajpura A and Board T. Current concepts in acetabular positioning in total hip arthroplasty. Indian J Orthop 2017; 51: 386-396.

2. Murray $D$. The definition and measurement of acetabular orientation. J Bone Joint Surg Br 1993; 75: 228-232.

3. Wan Z, Malik A, Jaramaz B, et al. Imaging and navigation measurement of acetabular component position in THA. Clin Orthop Relat Res 2009; 467: 32-42.

4. Archbold HA, Mockford B, Molloy D, et al. The transverse acetabular ligament: an aid to orientation of the acetabular com- 
ponent during primary total hip replacement: a preliminary study of 1000 cases investigating postoperative stability. J Bone Joint Surg Br 2006; 88: 883-886.

5. Beverland DE, O'Neill CK, Rutherford M, et al. Placement of the acetabular component. Bone Joint J 2016; 98(1 Suppl A): 37-43.

6. Hill JC, Gibson DP, Pagoti R, et al. Photographic measurement of the inclination of the acetabular component in total hip replacement using the posterior approach. J Bone Joint Surg Br 2010; 92: 12091214.
7. O'Neill CK, Magill P, Hill JC, et al. Correction of pelvic adduction during total hip arthroplasty reduces variability in radiographic acetabular inclination: findings of a randomised controlled trial. Hip Int 2018; 28: 240-246.

8. Barrack RL, Krempec JA, Clohisy JC, et al. Accuracy of acetabular component position in hip arthroplasty. J Bone Joint Surg Am 2013; 95: 1760-1768.

9. Honl M, Schwieger K, Salineros M, et al. Orientation of the acetabular component. A comparison of five navigation systems with conventional surgical technique. J Bone Joint Surg Br 2006; 88: 1401-1405. 